\title{
ASPECTOS FUNCIONAIS, MICROBIOLÓGICOS E MORFOLÓGICOS INTESTINAIS EM CRIANÇAS INFECTADAS PELO VÍRUS DA IMUNODEFICIÊNCIA HUMANA
}

\author{
Christiane Araujo Chaves LEITE ${ }^{1}$, Regina Célia de Menezes SUCCI ${ }^{2}$, \\ Francy Reis da Silva PATRÍCIO ${ }^{3}$ e Ulysses FAGUNDES-NETO ${ }^{4}$
}

RESUMO - Racional - O trato gastrointestinal é freqüentemente acometido nas crianças infectadas pelo vírus da imunodeficiência humana, com importantes repercussões no seu estado nutricional e sobrevida. A maioria dos estudos relacionados a esse tema foi desenvolvida com adultos, sendo menos investigado o problema nas crianças. Objetivos - Estudar aspectos digestivoabsortivos, microbiológicos e morfológicos intestinais em crianças infectadas pelo vírus da imunodeficiência humana. Material e métodos - Onze crianças infectadas pelo vírus da imunodeficiência humana, menores de 13 anos, pertencentes às categorias clínicas A, B ou C, divididas em dois grupos: cinco pacientes com relato atual ou recente de diarréia e seis pacientes sem diarréia nos 30 dias que antecederam à inclusão no estudo. Investigação proposta: biopsia de intestino delgado e reto para análise morfológica e microbiológica, coprocultura, protoparasitológico de fezes, pesquisa de rotavírus, micobactérias e Cryptosporidium; teste da D-xilose. Resultados - Todos os pacientes testados (9/11) apresentavam má absorção da D-xilose (8,4-24,4 mg/dL). Os achados histopatológicos de intestino delgado foram inespecíficos, representados em sua maioria, por enteropatia grau I a II (6/10). Em todos os casos foi constatado aumento do infiltrado celular do córion. As alterações histopatológicas do reto também foram inespecíficas, com presença de aumento do infiltrado celular do córion. A pesquisa de microorganismos enteropatogênicos só foi positiva em dois casos, sendo identificado Mycobacterium avium intracellulare e Cryptosporidium nas fezes. Conclusões - Demonstrou-se alta prevalência (100\%) de má absorção intestinal em crianças infectadas pelo vírus da imunodeficiência humana, com ou sem diarréia. Não foi possível estabelecer correlações quanto à presença de agentes enteropatogênicos, má absorção intestinal, alterações morfológicas intestinais e ocorrência ou não de diarréia. Não houve correlação entre os valores de D-xilose e os graus de atrofia vilositária.

DESCRITORES - Síndrome de imunodeficiência adquirida. Infecções por HIV. Síndromes de má absorção. Criança.

\section{INTRODUÇÃO}

A infecção pelo vírus da imunodeficiência humana (HIV) pode afetar todo o trato gastrintestinal e o sistema hepatobiliar ${ }^{(9)}$. Trata-se de síndrome com gênese multifatorial, envolvendo a interação entre infecções oportunistas, má absorção de nutrientes, alterações metabólicas e, possivelmente, lesão tecidual determinada pelo próprio $\mathrm{HIV}^{(13,14)}$. O trato gastrointestinal, por representar o maior órgão linfóide do ser humano, tem papel destacado na infecção pelo HIV. Com exceção da transmissão parenteral, o trato gastrointestinal é a principal via de infecção pelo HIV por transmissão vertical e por contato oral e genital.
Os linfócitos da lâmina própria, por expressarem CCR5 e CXCR4, constituem a célula alvo inicial do HIV na mucosa intestinal. Desde a mucosa, o vírus se dissemina sistemicamente, desencadeando depleção das células $\mathrm{CD} 4+$, inicialmente na lâmina própria e, em seguida, no sangue. À medida que ocorre a depleção de linfócitos CD4+ circulantes e na mucosa, monócitos e macrófagos assumem importância crescente como célula alvo e reservatórios do HIV $^{(28)}$. A infecção pelo HIV determina, portanto, falência progressiva das funções fisiológicas e imunológicas do trato gastrointestinal. Os pacientes podem, então, apresentar má absorção, perda de peso e desenvolver infecções oportunistas e doenças malignas do intestino ${ }^{(19)}$.

Trabalho realizado na Disciplina de Gastroenterologia Pediátrica do Departamento de Pediatria da Universidade Federal de São Paulo - Escola Paulista de Medicina, São Paulo, SP. ${ }^{1}$ Faculdade de Medicina da Universidade Federal do Ceará, Fortaleza, CE; ${ }^{2}$ Disciplina de Infectologia Pediátrica, ${ }^{3}$ Departamento de Patologia, ${ }^{4}$ Disciplina de Gastroenterologia Pediátrica da Universidade Federal de São Paulo - Escola Paulista de Medicina, São Paulo, SP. Endereço para correspondência: Dra. Christiane A. Chaves Leite - Rua Cel. Linhares, 511 - apt. 1001 - Meireles - 60170-240 - Fortaleza, CE. E-mail: chrisgastroped@webcabo.com.br 
As principais alterações morfológicas descritas no intestino delgado dos pacientes infectados pelo HIV são atrofia das vilosidades de grau variável, hiperplasia das criptas e aumento dos linfócitos intra-epiteliais, associadas ou não à presença de sintomas ou microorganismos, observadas em qualquer estágio da doença, sugestivas de uma enteropatia do $\mathrm{HIV}^{(16)}$. No intestino grosso, tem sido observado grau de inflamação da mucosa comparável ao daquele em pacientes com doença inflamatória intestinal ${ }^{(24)}$. $\mathrm{Na}$ investigação microbiológica do trato gastrointestinal podem ser identificados diversos microorganismos, oportunistas ou não, cujo encontro nem sempre está associado a manifestações clínicas. Os testes para avaliação da função intestinal mostram, freqüentemente, prejuízo na absorção nos diversos estágios da doença ${ }^{(11,17)}$.

Tendo em vista a importância do impacto das manifestações gastrointestinais da infecção pelo HIV em crianças e a escassez de informações a respeito em nosso meio, conduziu-se o presente estudo objetivando ampliar conhecimentos acerca da função absortiva e das características morfológicas e microbiológicas intestinais nesse grupo.

\section{MATERIAL E MÉTODOS}

\section{Casuística}

Foram selecionadas aleatoriamente, de forma prospectiva e consecutiva, entre agosto de 1994 e maio de 1995, 11 crianças infectadas pelo HIV, menores de 13 anos, pertencentes às categorias clínicas $\mathrm{A}$, $\mathrm{B}$ ou $\mathrm{C}$ da classificação proposta pelos Centers for Diseases Control and Prevention (CDC) $)^{(6)}$ no Ambulatório de AIDS da Disciplina de Infectologia do Departamento de Pediatria da Universidade Federal de São Paulo - Escola Paulista de Medicina (UNIFESP - EPM) e na Enfermaria e Ambulatório do Núcleo de Nutrição, Alimentação e Desenvolvimento Infantil (NUNADI) do Centro de Referência da Saúde da Mulher da Secretaria da Saúde de São Paulo, em São Paulo, SP. Foram constituídos dois grupos, a saber: grupo I - cinco crianças com história de pelo menos um episódio diarréico nos 30 dias que antecederam sua inclusão no estudo; grupo II - seis crianças, sem relato de ocorrência de diarréia no mesmo período. O estudo foi aprovado pelo Comitê de Ética em Pesquisa da UNIFESP-EPM, sendo obtido consentimento escrito e esclarecido dos pais ou responsáveis legais pelas crianças. Os hemofílicos soropositivos para o HIV só foram incluídos no estudo quando havia indicação clínica absoluta para realização de endoscopia digestiva alta.

$\mathrm{Na}$ admissão ao estudo foi preenchido um questionário padronizado com informações clínicas e epidemiológicas, seguido pela aferição do peso e estatura para classificação do estado nutricional segundo os critérios de Gomez modificados por BENGOA ${ }^{(4)}$ e Waterlow modificados por BATISTA et al. ${ }^{(2)}$, tendo como referência de normalidade as tabelas de percentis do National Center for Health Statistics (NCHS).

\section{INVESTIGAÇÃO LABORATORIAL}

Teste de absorção da D-xilose

Após jejum de 4 horas os pacientes receberam $0,5 \mathrm{~g}$ de $\mathrm{D}$-xilose (diluída em solução aquosa a 10\%) por kg de peso, até um máximo de
25 g. Uma hora após sua administração, foi coletada amostra de sangue para determinação da $\mathrm{D}$-xilose sérica pelo método colorimétrico, de acordo com técnica descrita por ROE e RICE ${ }^{(2)}$. Valores menores que $25 \mathrm{mg} / \mathrm{dL}$ foram considerados como indicativos de má absorção.

\section{Cultura e parasitológico de fezes}

As amostras de fezes foram cultivadas nos meios SS, BEM e tetrationato para identificação de Escherichia coli, Salmonella e Shigella e nos meios Lowenstein Jensen e Stonebrink para identificação de micobactérias. A pesquisa de micobactérias também foi realizada por baciloscopia, usando-se a coloração de Ziehl-Nielsen. Rotavírus foi pesquisado pelos métodos imunoenzimático e de aglutinação no látex. A pesquisa de parasitas e helmintos foi realizada pelos métodos de Hoffman, centrífugo de sedimentação em formol-éter e de Rugai. Cryptosporidium foi investigado pelo método de Ziehl-Nielsen.

\section{Biopsia de intestino delgado}

A biopsia de intestino delgado foi realizada com utilização de uma sonda flexível de polietileno acoplada a uma cápsula de Watson na extremidade distal, segundo a técnica descrita por TOCCALINO e O'DONNEL ${ }^{(29)}$, ou através de pinça endoscópica, nos casos em que o procedimento por cápsula não foi possível ser realizado ou com indicação clínica prévia de realização de endoscopia digestiva alta. Os fragmentos obtidos foram submetidos as colorações de hematoxilinaeosina, Giemsa, PAS, Prata e Ziehl-Nielsen e, nas amostras de tamanho satisfatório, foi realizada a pesquisa de micobactérias em tecido, segundo metodologia anteriormente descrita para as fezes. A interpretação dos fragmentos por microscopia óptica foi baseada na relação entre a altura das vilosidades e a profundidade das criptas e na intensidade do infiltrado inflamatório da lâmina própria, segundo critérios modificados de SHENCK e KLIPSTEIN ${ }^{(27)}$. Assim, os parâmetros histológicos avaliados foram:

a) altura ou comprimento da vilosidade da abertura da cripta até o topo da vilosidade;

b) comprimento ou profundidade da cripta da abertura até o fundo da cripta que repousa sobre a muscular da mucosa. A relação entre a altura da vilosidade e a profundidade da cripta foi avaliada subjetivamente do seguinte modo: grau I - relação entre 3 a 2 para 1: sem atrofia ou em grau muito leve, praticamente dentro da normalidade; grau II - relação 1 para 1: atrofia leve; grau III - já existe inversão da relação vilosidade/cripta, isto é, cripta pouco mais longa que a vilosidade: atrofia moderada, também chamada atrofia parcial; grau IV - mucosa plana por intensa atrofia das vilosidades, também chamada atrofia subtotal;

c) infiltrado celular da lâmina própria, constituído por linfócitos, plasmócitos e eosinófilos, avaliado em graus leve ou normal, moderado e intenso. Polimorfonucleares neutrófilos, que não existem na mucosa intestinal normal, quando ocorreram, foram também classificados em graus leve, moderado e intenso;

d) linfócitos intra-epiteliais, que ocorrem normalmente no intestino delgado em número de até 30 por 100 enterócitos, foram avaliados em graus de aumento leve ( 30 a 40 por 100 enterócitos), moderado (entre 40 e 50 por 100 enterócitos) e intenso (acima de 60 por 100 enterócitos). 


\section{Biopsia retal}

A biopsia retal foi realizada com utilização da cápsula de Rubin. Os fragmentos obtidos foram submetidos as colorações de hematoxilinaeosina, Giemsa, PAS, Prata e Ziehl-Nielsen e, nas amostras de tamanho satisfatório, foi realizada a pesquisa de micobactérias em tecido, segundo metodologia anteriormente descrita para as fezes. A avaliação morfológica dos fragmentos de intestino grosso foi realizada por microscopia óptica, de acordo com os critérios de $\mathrm{MORSON}^{(22)}$, considerando-se a análise da integridade do epitélio superficial (erosões), das glândulas e o infiltrado de linfócitos, plasmócitos e eosinófilos nos graus de intensidade leve, moderado e intenso.

\section{RESULTADOS}

A idade das crianças variou de 5 a 149 meses (mediana de 24 meses), sendo seis do sexo feminino e cinco do sexo masculino. Nos 30 dias que antecederam à inclusão no estudo, cinco crianças haviam apresentado diarréia, das quais três já assim se mostravam desde o início da investigação. Outros sintomas digestivos referidos foram vômitos (4/11), disfagia (1/11) e dor abdominal (1/11). Os medicamentos usados foram: zidovudina (9/11), didanosina (3/11), sulfametoxazol-trimetoprim (10/11), imunoglobulina intravenosa $(2 / 11)$, nistatina (2/11), azitromicina (1/11) e associação de rifampicina, isoniazida e pirazinamida (1/11). Das 11 crianças, 9 foram infectadas pelo HIV por transmissão vertical, 1 por transfusão de hemoderivados (hemofílico) e 1 permanecia com modo de transmissão não esclarecido.

Segundo os critérios de Gomez modificados por BENGOA ${ }^{(4)}$, para avaliação do estado nutricional, todas as 11 crianças apresentavam algum grau de desnutrição energético-protéica, sendo 6 de III grau, 2 de II grau e 1 de I grau. Já pelos critérios de Waterlow modificados por BATISTA et al. ${ }^{(2)}$, aplicado para as duas crianças maiores de 5 anos, houve um caso de desnutrição pregressa e um de desnutrição crônica.
Coprocultura, realizada em 7 dos 11 pacientes, não identificou bactérias enteropatogênicas. Pesquisa de rotavírus foi negativa nas seis crianças em que foi realizada e o exame protoparasitológico também foi negativo nas oito crianças das quais foram obtidas amostras adequadas de fezes. Cryptosporidium foi identificado em 1 e o resultado foi duvidoso em outro dos 10 exames realizados. Dos cinco casos em que foi possível pesquisar, Mycobacterium avium intracellulare foi identificado em apenas uma amostra de fezes. A pesquisa de Mycobacterium avium intracellulare nos fragmentos de biopsia resultou negativa nas seis amostras investigadas, inclusive na do paciente em que foi identificado este microorganismo nas fezes.

A prova de absorção da D-xilose foi realizada em 9 dos 11 pacientes, com valores variando de 8,9 a $24,4 \mathrm{mg} / \mathrm{dL}$, média de $15,6 \mathrm{mg} / \mathrm{dL}$, mediana de $14,2 \mathrm{mg} / \mathrm{dL}$ e desvio padrão de $5 \mathrm{mg} / \mathrm{dL}$.

Dos 11 fragmentos de biopsias de intestino delgado obtidos, 1 foi excluído da análise por ser tecnicamente inadequado para exame (Tabela 1). Quanto à relação entre altura das vilosidades e profundidade das criptas, os resultados foram os seguintes: três com atrofia de vilosidades grau I(Figura 1), dois com grau I/II, um com grau II, um com grau II/III e um com grau III/IV. Em dois casos não foi possível análise deste parâmetro, pois as amostras eram superficiais. Linfócitos intra-epiteliais foram observados nos 10 fragmentos analisados (Figura 1), estando aumentados em 5, sendo 2 em quantidade leve, 2 em quantidade moderada e 1 em quantidade intensa. $O$ infiltrado linfoplasmocitário da lâmina própria estava aumentado em 100\% das amostras analisadas (10/10) e foi graduado em moderado (4/10), intenso (5/10), como se pode observar na Figura 2-A, e leve (1/10). $\mathrm{O}$ infiltrado de polimorfonucleares neutrófilos da lâmina própria estava aumentado em 7 das 10 amostras analisadas. Destas, três em grau leve, quatro em grau moderado e um em grau intenso. Em apenas um caso foi observada presença de microorganismos em forma de bastões, similares a bactérias, em meio ao muco que recobria o epitélio. Nesta amostra, uma crosta fibrino-leucocitária no topo da vilosidade fez supor lesão ulcerada.

TABELA 1 - Idade, classificação clínica da infecção pelo HIV, teste da D-xilose e resultados dos exames histopatológicos dos fragmentos de biopsia de intestino delgado de crianças HIV

\begin{tabular}{|c|c|c|c|c|c|c|c|c|c|}
\hline \multirow{2}{*}{ Paciente } & \multirow{2}{*}{$\begin{array}{c}\text { Idade } \\
\text { (meses) }\end{array}$} & \multirow{2}{*}{$\begin{array}{l}\text { Classificação } \\
\text { clínica }\end{array}$} & \multirow{2}{*}{ Diarréia } & \multirow{2}{*}{$\begin{array}{l}\text { D-xilose } \\
(\mathrm{mg} / \mathrm{dL})\end{array}$} & \multirow{2}{*}{$\begin{array}{c}\text { Atrofia } \\
\text { Vilositária } \\
\text { (grau) }\end{array}$} & \multirow{2}{*}{$\begin{array}{c}\text { Linfócitos } \\
\text { intra- } \\
\text { epiteliais* }\end{array}$} & \multicolumn{2}{|c|}{$\begin{array}{c}\text { Lâmina } \\
\text { Própria* } \\
\end{array}$} & \multirow{2}{*}{ Conclusão } \\
\hline & & & & & & & $\operatorname{ILP} \dagger$ & IPMNN‡ & \\
\hline 1 & 35 & A & Não & 20,5 & $\mathrm{I} / \mathrm{II}$ & $\mathrm{L}$ & I & $\mathrm{L}$ & Enteropatia Grau I/II. Grande aumento do ILP do córion \\
\hline 2 & 11 & $\mathrm{C}$ & Não & 8,9 & II & M & I & I & $\begin{array}{l}\text { Intenso infiltrado IPMNN do córion. Bactérias no muco } \\
\text { intestinal. Crosta fibrino-leucocitária sugere lesão ulcerada }\end{array}$ \\
\hline 3 & 6 & $\mathrm{C}$ & $\operatorname{Sim}$ & 13,3 & $\mathrm{I} / \mathrm{II}$ & normal & M & $\mathrm{L}$ & Enteropatia grau I/II \\
\hline 4 & 9 & $\mathrm{C}$ & Não & 24,4 & & iação prejudicada & & & Inconclusivo \\
\hline 5 & 14 & $\mathrm{C}$ & Sim & 14,2 & I & $\mathrm{L}$ & M & M & $\begin{array}{c}\text { I } \\
\text { Enteropatia grau }\end{array}$ \\
\hline 6 & 149 & $\mathrm{C}$ & Não & 16,2 & I & normal & M & A & Enteropatia grau I. Moderado ILP do córion \\
\hline 7 & 12 & $\mathrm{C}$ & Sim & 12,2 & $\begin{array}{l}\text { Biopsias } \\
\text { superficiais }\end{array}$ & normal & I & $\mathrm{L}$ & Intenso ILP do córion. Raros eosinófilos \\
\hline 8 & 10 & B & Não & NR§ & III/IV & normal & I & M & $\begin{array}{l}\text { Enteropatia grau IV. Eosinofilia e intenso ILP do córion } \\
\text { (Figura 2A) }\end{array}$ \\
\hline 9 & 10 & $\mathrm{C}$ & Sim & NR§ & $\mathrm{II} / \mathrm{III}$ & normal & $\mathrm{L}$ & normal & Enteropatia Grau II/III. Leve aumento do ILP do córion \\
\hline 10 & 30 & B & Não & 13,5 & I & I & I & $\mathrm{L}$ & Enteropatia Grau I. Intenso ILP do córion (Figura 1) \\
\hline 11 & 100 & B & Sim & 17,5 & $\begin{array}{c}\text { Avaliação } \\
\text { prejudicada }\end{array}$ & M & M & M & $\begin{array}{l}\text { Lesões importantes: perda da polaridade nuclear, perda da } \\
\text { borda estriada e vacuoloização. Moderado ILP do córion }\end{array}$ \\
\hline
\end{tabular}




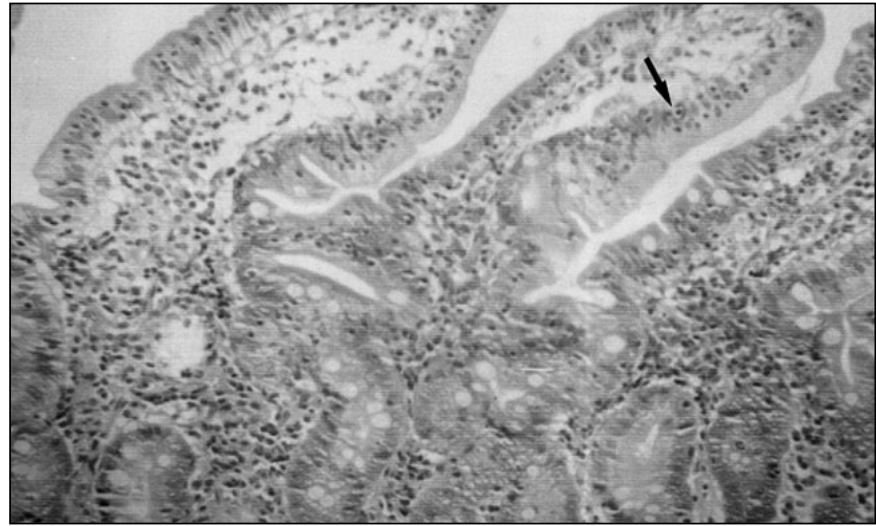

FIGURA 1 - Enteropatia grau I com intenso aumento do infiltrado linfoplasmocitário do córion. Note-se o aumento de leucócitos intra-epiteliais (seta). Microscopia óptica de intestino delgado (aumento de 16x). Coloração hematoxilina-eosina
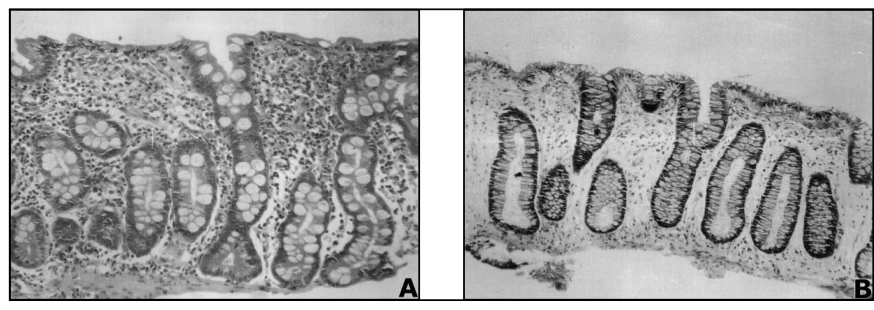

FIGURA 2 -Comparação entre dois exames histopatológicos de intestino delgado (A) e grosso (B) quanto ao aumento infiltrado linfoplasmocitário do córion, que se mostra intenso em (A) e leve em (B) Microscopia óptica de intestino delgado e grosso (aumento 16x). Coloração hematoxilina-eosina (A) e Giemsa (B)

Foram realizadas oito biopsias retais e, destas, seis se prestaram à análise histopatológica. Quanto à integridade epitelial, em 100\% (6/6) dos casos mostrava-se íntegra. O infiltrado linfoplasmocitário estava aumentado em todos os casos, variando de grau leve (3/6), como se observa na Figura 2-B, moderado $(2 / 6)$ e intenso $(1 / 6)$. A presença de infiltrado de polimorfonucleares neutrófilos foi observada em quatro casos, sendo de grau leve em três e intenso em um (Tabela 2 e Figura 3).

TABELA 2 - Resultados dos exames histopatológicos dos fragmentos de biopsia retal realizadas em crianças $\mathrm{HIV}^{+}$

\begin{tabular}{|c|c|c|c|c|}
\hline \multirow{2}{*}{ Paciente } & \multirow{2}{*}{ Epitélio } & \multicolumn{2}{|c|}{ Lâmina própria* } & \multirow{2}{*}{ Conclusão } \\
\hline & & $\mathrm{ILP} \dagger$ & IPMN: & \\
\hline 1 & Íntegro & M & A & Moderado aumento do ILP do córion \\
\hline 2 & Íntegro & $\mathrm{L}$ & $\mathrm{L}$ & Leve aumento do ILP do córion \\
\hline 3 & Íntegro & $\mathrm{L}$ & A & Leve aumento do ILP do córion \\
\hline 4 & \multicolumn{3}{|c|}{ Não analisado } & Não obtido fragmento com elementos de mucosa retal \\
\hline 5 & Íntegro & $\mathrm{L}$ & $\mathrm{L}$ & $\begin{array}{l}\text { Edema, congestão vascular e leve aumento do ILP, } \\
\text { com área de transição anorretal (Figura 2B) }\end{array}$ \\
\hline 6 & \multicolumn{3}{|c|}{ Não analisado } & $\begin{array}{c}\text { Fragmento insuficiente para exame. Presença de } \\
\text { hemorragia }\end{array}$ \\
\hline 7 & Íntegro & $\mathrm{L}$ & $\mathrm{L}$ & Normal \\
\hline 8 & \multicolumn{3}{|c|}{ Não analisado } & Não realizada biopsia retal \\
\hline 9 & \multicolumn{3}{|c|}{ Não analisado } & Não realizada biopsia retal \\
\hline 10 & Íntegro & M & M & $\begin{array}{l}\text { Colite ativa focal com leucócitos intra-epiteliais, } \\
\text { inclusive polimorfonucleares (Figura 3) }\end{array}$ \\
\hline 11 & \multicolumn{3}{|c|}{ Não analisado } & Não realizada biopsia retal \\
\hline
\end{tabular}
† ILP $=$ infiltrado linfoplasmocitário
ҒIPMN $=$ infiltrado polimorfonuclear

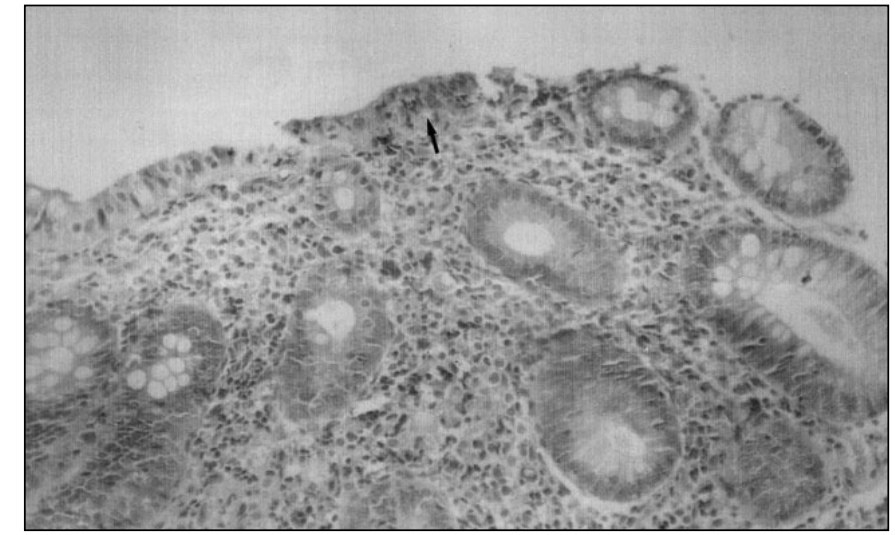

FIGURA 3 - Colite ativa focal (seta). Presença de leucócitos intra-epiteliais e eosinófilos. Microscopia óptica de intestino grosso (aumento 16x). Coloração hematoxilina-eosina

\section{DISCUSSÃO}

Este estudo foi realizado em período que antecedeu o advento da terapia anti-retroviral potente (HAART), no qual se dispunha apenas de monoterapia ou uso combinado de dois anti-retrovirais análogos de nucleosídios e, portanto, pequeno impacto clínico, imunológico e virológico na evolução da infecção pelo HIV. Sendo assim, a presente amostra deve representar condição muito próxima à observada na história natural da infecção pelo HIV nas crianças. Esta observação é importante, pois, ao se compararem biopsias de intestino de pacientes HIV positivos entre 1995 e 1998, período em que foi introduzida a HAART, MÖNKEMÜLLER et al. ${ }^{(20)}$ constataram declínio significativo das infecções oportunistas gastrointestinais, mesmo nos indivíduos com CD4 baixo. De modo diverso, estudo conduzido na região sul do Brasil em 1999, envolvendo 104 crianças infectadas pelo HIV e já em uso de HAART, identificou a presença de Cryptosporidium em $31,73 \%$ das amostras de fezes analisadas ${ }^{(25)}$. Este mesmo estudo, no entanto, atribui ao uso da HAART a escassez de alteração no teste da D-xilose, observada em apenas 7,7\% das crianças. Outro estudo envolvendo coorte de 671 pacientes infectados pelo HIV, entre 1995 e 1999, mostrou que 47,7\% apresentavam má absorção de D-xilose, $38,9 \%$ tinham diarréia e que em $12,2 \%$ foram identificados agentes patogênicos entéricos, sendo encontrado Cryptosporidium em apenas uma amostra de fezes. A identificação de microorganismos patogênicos nas fezes não tinha associação com ocorrência de diarréia. Esse estudo concluiu que a alteração da função gastrointestinal é também problema comum após o advento da HAART, tendo início precoce na evolução da infecção pelo HIV, mesmo na ausência de diarréia. A explicação para resultados tão distintos enfatiza a complexidade da interação de fatores sociodemográficos, exposição a agentes patogênicos diversos e estágio da infecção pelo HIV capazes de afetar a função gastrointestinal ${ }^{(15)}$.

Embora com casuística pequena e num contexto de disponibilidade de arsenal terapêutico diferente, os resultados da presente série se assemelham aos reportados na literatura. Três dos 11 pacientes apresentavam diarréia. No entanto, os dois microorganismos oportunistas identificados, Cryptosporidium e Mycobacterium avium intracellulare, não estavam associados à ocorrência de diarréia. Ainda nesta casuística, o teste da D-xilose esteve abaixo do nível normal 
nos nove pacientes em que foi realizado, independentemente da ocorrência de diarréia como sintoma de má absorção, fato também relatado por outros autores ${ }^{(16,17)}$. O paciente em que se identificou Mycobacterium avium intracellulare teve a D-xilose de valor mais baixo, ainda que com apenas grau II de atrofia de vilosidades no fragmento de intestino delgado obtido por biopsia. O encontro de má absorção da D-xilose, mesmo com alterações histológicas mínimas da mucosa intestinal, também já foi descrito, podendo os resultados alterados representar uma predição da ocorrência da enteropatia pelo $\mathrm{HIV}^{(5,10)}$. KNOX et al. ${ }^{(15)}$ verificaram em sua casuística que a má absorção da D-xilose ocorreu em indivíduos sem outros sinais de má absorção, tais como diarréia, baixos níveis de vitamina B12 e de folatos no sangue ou perda de gordura nas fezes. Tais dados seriam sugestivos de que as alterações precoces determinadas pela enteropatia pelo HIV sejam freqüentes, porém não detectáveis, exceto por absorção alterada da D-xilose.

A análise histológica dos fragmentos de intestino delgado no presente estudo, mostrou graus variados de atrofia das vilosidades, alteração da relação altura da vilosidade versus profundidade da cripta nos oito casos em que a biopsia permitiu essa avaliação, infiltrado inflamatório crônico com predomínio de células linfomononucleares na maioria das amostras e aumento de linfócitos intra-epiteliais na metade dos casos analisados. Essas alterações não estavam correlacionadas com ocorrência de diarréia, nem com a presença de microorganismos ou alteração do teste da D-xilose, conforme descrito anteriormente. Inclusive, o paciente com grau mais intenso de atrofia vilositária (grau III/IV) desta casuística, não apresentava diarréia. Este polimorfismo das alterações estruturais do intestino e a nem sempre possível associação com ocorrência de sintomas clínicos, encontro de microorganismos e provas de absorção alteradas levou a hipótese da enteropatia pelo HIV, pioneiramente sugerida por KOTLER et al. ${ }^{(16)} \mathrm{e}$ ULLRICH et al. ${ }^{(30)}$. Embora não se tenha realizado análise morfométrica, os achados histológicos desta série parecem coincidir, em alguns aspectos, com os descritos por BATMAN et al. ${ }^{(3)}$ em estudo comparativo da morfometria da mucosa jejunal de pacientes infectados pelo HIV residentes em Uganda e Londres. Esses autores, a partir da observação de uma correlação negativa entre o comprimento das criptas e a área da superfície das vilosidades em todas as biopsias realizadas, sugerem que a hiperplasia das células da cripta constitui a lesão primária da mucosa na enteropatia, conduzindo enterócitos imaturos para as laterais das vilosidades e reduzindo a área de absorção das vilosidades através do deslocamento da junção cripta-vilosidade em direção ao lúmen. Sugerem, ainda, que a infecção das células da lâmina própria do jejuno pelo HIV alteraria a regulação de citocinas e estimularia a proliferação de células das criptas, resultando na lesão de mucosa observada na enteropatia do HIV. Segundo MARSH ${ }^{(18)}$, este tipo de atrofia com hiperplasia de criptas e atrofia de vilosidades, que pode chegar à mucosa plana, observada também na doença celíaca e em outras enteropatias, seria causado por mecanismos regulados por linfócitos T. OKTEDALEN et al. ${ }^{(23)}$, estudando 20 pacientes infectados pelo HIV com diarréia, constataram um padrão de má absorção da D-xilose comparável ao observado em pacientes com doença celíaca. No entanto, esse acentuado comprometimento na absorção intestinal não pôde ser explicado pelas alterações observadas pela microscopia de luz dos fragmentos de intestino delgado, isto é, pouca inflamação da mucosa e vilosidades normais. Já a microscopia eletrônica mostrou enterócitos com sinais de hipofunção e degeneração e, portanto, correlacionando-se bem com o quadro de má absorção intestinal em pacientes com infecção avançada pelo HIV e diarréia crônica. Experimentos mais recentes in vitro demonstraram que a glicoproteína 120 (gp 120) do HIV, ao acoplar-se com a proteína receptora GPR15/Bob, que existe em abundância na membrana basal do intestino delgado, induz à sinalização de cálcio e perda de microtúbulos nas células de linhagem intestinal HT-29, resultando em má absorção e aumento na permeabilidade paracelular, configurando mecanismo plausível para a enteropatia do $\mathrm{HIV}^{(7)}$.

Nas seis crianças deste estudo, nas quais foi possível fazer a análise morfológica das biopsias retais, destaca-se o encontro de infiltrado linfomononuclear aumentado em todas as amostras e de infiltrado polimorfonuclear neutrófilo em quatro das amostras, caracterizando quadro de infiltrado inflamatório não específico, também descrito na literatura. A presença dos neutrófilos indica atividade da lesão, isto é, fase de reagudização da lesão, já que essas células não ocorrem normalmente na lâmina própria do trato gastrointestinal. CLAYTON et al. ${ }^{(8)}$ documentaram progressão qualitativa e quantitativa nas alterações vistas na mucosa retal de indivíduos infectados pelo HIV, a qual se correlacionou com a presença e a quantidade do vírus no tecido colônico, sugerindo, além da enteropatia do HIV anteriormente comentada, que a mucosa intestinal poderia constituir local de proliferação e de destruição de linfócitos. Mais recentemente, MONNO et al. ${ }^{(21)}$, comparando amostras de HIV obtidas concomitantemente do sangue e de tecido retal, verificaram padrões de resistência aos anti-retrovirais diferentes, dando suporte à idéia de evolução genotípica variável do HIV nos diferentes compartimentos corporais e enfatizando a participação da mucosa intestinal na seleção do genótipo do HIV.

Desnutrição, na presente casuística, esteve presente em todas as crianças, na maioria em sua forma grave (III grau), quando consideradas as menores de 5 anos, denotando o impacto da infecção pelo HIV nesses pacientes. Já a avaliação das duas crianças maiores de 5 anos evidencia agravo nutricional de longa duração, tendo em vista o comprometimento da estatura de ambos. Não se pode desprezar o efeito que o meio ambiente adverso, ao qual essas crianças são submetidas, exerce nesse contexto, pois algumas delas identificavam-se perfeitamente na descrição da síndrome que FAGUNDES-NETO et al. ${ }^{\left({ }^{(2)}\right)}$ denominaram de enteropatia ambiental, em que são observados graus variáveis de atrofia das vilosidades e infiltrado linfoplasmocitário do córion, à semelhança dos resultados do estudo presente. A desaceleração do crescimento ponderal e de estatura parece ser a alteração mais comum nas crianças infectadas pelo HIV e é acompanhada por decréscimo preferencial da gordura livre ou da massa corporal magra. Podem estar associadas deficiências de vários micronutrientes, alterações neuroendócrinas, infecções do trato gastrointestinal e má absorção de carboidratos, gordura e proteína na gênese desse processo. As crianças infectadas pelo HIV que têm crescimento retardado, apresentam cargas virais mais elevadas quando comparadas com as que têm crescimento normal e a supressão do HIV parece exercer papel favorável na retomada do ganho ponderal e da estatura. Estuda-se, atualmente, o potencial dos agentes anabolizantes no manuseio clínico dessa condição ${ }^{(1)}$.

Os dados deste estudo são compatíveis com os descritos na literatura, embora se tenham encontrado apenas lesões histológicas sem especificidade. Considerando-se a escassez de informações sobre o trato gastrointestinal em crianças infectadas pelo HIV, os resultados da presente série contribuem para melhor compreensão da evolução 
da infecção pelo HIV na faixa etária pediátrica. Um passo futuro, seria avançar na análise ultra-estrutural para melhor caracterizar a enteropatia do HIV, bem como avaliar o impacto da má absorção intestinal na biodisponibilidade dos medicamentos anti-retrovirais e a busca de estratégias de suporte nutricional específicas para esses pacientes.

\section{AGRADECIMENTO}

Agradecemos à Coordenação de Aperfeiçoamento de Pessoal de Ensino Superior (CAPES) pela bolsa de mestrado da Dra. Christiane Araujo Chaves Leite.

Leite CAC, Succi RCM, Patrício FRS, Fagundes-Neto U. Functional, microbiological and morphological intestinal findings among human immunodeficiency virus infected children. Arq Gastroenterol. 2006;43(4):310-5.

ABSTRACT - Background - Gastrointestinal tract disorders are frequent among human immunodeficiency virus infected children, with important repercussions on nutrition and survival. Most studies related to this subject were restricted to adults, being less investigated the problem in the children. Aims - To study intestinal digestion, absorption, microbiological and morphological findings among human immunodeficiency virus infected children. Material and methods -Eleven human immunodeficiency virus infected children under 13 years old, belonging to clinical categories $\mathrm{A}, \mathrm{B}$ or $\mathrm{C}$, separated in two groups: five patients with current or recent episode of diarrhea and six patients without diarrhea in the last 30 days preceding entering in study. Investigation proposed: microbiological and morphological analysis of small intestine and rectum biopsy; stool exams for bacterium, parasite, rotavirus, Mycobacterium species and Cryptosporidium; D-xylose test. Results - All tested subjects (9/11) had low D-xylose absorption $(8,4-24,4 \mathrm{mg} \mathrm{d} / \mathrm{L})$. Small intestinal mucosa histology findings were nonspecific, represented, in majority, of grade I/II enteropathy (6/10). Increased cellular infiltration of the chorion was observed in all specimens. Rectum histology alterations were also nonspecific, with chorion increased cellular infiltration. Mycobacterim avium intracellulare and Cryptosporidium were the solely microorganisms founded, both in stool. Conclusions - Our study demonstrated high prevalence (100\%) of intestinal malabsorption among human immunodeficiency virus infected children, despite the occurrence or not of diarrhea. It was not possible to establish relationships between the presence of microorganisms, intestinal malabsorption, intestinal morphologic findings and the occurrence or not of diarrhea. There was no correlation between D-xylose and intensity of villous atrophy.

HEADINGS - Acquired immunodeficiency syndrome. HIV infections. Malabsorption syndromes. Child.

\section{REFERÊNCIAS BIBLIOGRÁFICAS}

1. Arpadi SM. Growth failure in children with HIV infection. J Aquir Immune Defic Syndr. 2000;25(Suppl 1):s37-s42.

2. Batista-Filho M, Sigulem DM, Nóbrega FJ. Nomenclatura e classificação de desnutrição. 1. Desnutrição protéico-calórica (DPC). J Pediatr.(Rio de Janeiro) 1976;41:45-51

3. Batman PA, Kapembwa MS, Miller ARO, Sedgwick PM, Lucas S, Sewankambo NK, Serwadda D, Pudney J, Moody A, Harris JR, Griffin GE. HIV enteropathy: comparative morphometry of the jejunal mucosa of HIV infected patients resident in the United Kingdom and Uganda. Gut. 1998;43:350-5.

4. Bengoa JM. The problem of malnutrition. WHO Chronicle. 1974;28:3-7.

5. Carlson S, Yokoo H, Craig RM. Small intestinal HIV-associated enteropathy: evidence for panintestinal enterocyte dysfunction. J Lab Clin Med. 1994:124:652-9.

6. Centers for Diseases Control and Prevention. Classification system for human immunodeficiency virus (HIV) infection in children under 13 years of age. MMWR. 1994;36:225-36.

7. Clayton F, Kotler DP, Kuwada SK, Morgan T, Stepan C, Kuang J, Le J, Fantini J. Gp 129-induced Bob/GPR15 activation: a possible cause of human immunodeficiency virus enteropathy. Am J Pathol. 2001;159:1933-9.

8. Clayton F, Reka S, Cronn WJ, Torlakovic E, Sigal SH, Kotler DP. Rectal mucosa pathology varies with human immunodeficiency virus antigens content and disease stage. Gastroenterology. 1992;103:919-33.

9. Edwards P, Wodak, A, Cooper DA, Thompson IL, Penny, R. The gastrointestinal manifestations of AIDS. Aust NZ J Med. 1990;20:141-8

10. Ehrenpreis ED, Gulino SP, Patterson BK, Craig RM, Yokoo H, Atkinson AJ Jr. Kinetic of D-xylose absorption in patients with human immunodeficiency virus enteropathy. Clin Pharmacol Therap. 1991;49:632-40.

11. Ehrenpreis, ED, Patterson, BK, Brainer JA, Yokoo, H, Rademaker AW, Glogshi W, Naskin GA, Craig GM. Histopathologic findings of duodenal biopsy specimens in HIV-infected patients with and without diarrhea and malabsorption. Am J Clin Pathol. 1992;97:21-8

12. Fagundes-Neto U, Viaro T, Wehba J, Patricio FRS, Machado NJ. Enteropatia ambienta na infância: uma síndrome decorrente da contaminação ambiental (enteropatia ambiental). J Pediatr.(Rio de Janeiro) 1983;54:313-9.

13. Griffin GE. Malabsorption, malnutrition and HIV disease. Baillieres Clin Gastroenterol 1990;4:361-73.

14. Grunfeld C, Feingold K. Metabolic disturbances and wasting in the acquired immunodeficiency syndrome. N Engl J Med. 1992:327:329-35.

15. Knox TA, Spiegelman D, Skinner SC, Gorbach S. Diarrhea and abnormalities of gastrointestinal function in a cohort of men and women with HIV infection. Am J Gastroenterol. 2000;95:3482-9.
16. Kotler DP, Gaetz HP, Langer M, Holt EB, Holt PR. Enteropathy associated with acquired immunodeficiency syndrome. Ann Intern Med. 1984;101:421-8.

17. Kotler DP, Reka S, Chow K, Orenstein IM. Effects of enteric parasitoses and HIV infection upon small intestinal structure and function in patients with AIDS. J Clin Gastroenterol. 1993:16:10-5.

18. Marsh MN. Gluten, major histocompatibility complex, and the small intestine: a molecular and immunobiologic approach to spectrum of gluten sensitivity (celiac sprue). Gastroenterology. 1992;102:330-54.

19. McGowan I, Chalmers A, Smith GR, Jewell D. Advances in mucosal immunology. Gastroenterol Clin North Am. 1997;26:145-73.

20. Mönkemüller KE, Call SA, Lazenby AJ, Wilcox CM. Declining prevalence of opportunistic gastrointestinal disease in the era at combination antiretroviral therapy. Am J Gastroenterol. 2000;95:457-62.

21. Monno L, Punzi G, Scarabaggio T, Saracino A, Brindicci G, Fiore JR, Iambrenghi OC, Di Stefano M, Pastoe G, Angarano G. Mutational patterns of paired blood and rectal biopsies in HIV-infected patients on HAART. J Med Virol. 2003;70:1-9.

22. Morson BC. The technique and interpretation of rectal biopsies in inflammatory bowel disease. In: Sommers SC, editor. Gastrointestinal and hepatic pathology decennial 1966-1975. New York: Appleton-Century-Crofts;c1975. p. 265.

23. Oktedalen O, Skar V, Dahl E, Sereck-Hanssen A. Changes in small intestinal structure and function in HIV-infected patients with chronic diarrhoea. Scand J Infect Dis. 1998;30:459-63.

24. Olsson J, Poles M, Spetz A-L, Elliot J, Hultin L, Giorgi J, Andersson J, Anton P. Human immunodeficiency virus type 1 infection is associated with significant mucocal inflammation characterized by increased expression of CCR5, CXCR4 and $\beta$-chemokines. JID 2000;182:1625-35.

25. Perin NM, Pires MMS, Nassar SM. Absorção intestinal de D-xilose em crianças infectadas pelo vírus da imunodeficiência humana. Arq Gastroenterol. 2001;38:261-8.

26. Roe JR, Rice EW. A photometric method for the determination of free pentoses in animal tissues. J Biol Chem; 1948;173:507-12.

27. Schenk EA, Klipstein FA. A protocol for the evaluation of small bowel biopsies. Am J Clin Nutr. 1972;25:1108-17

28. Smith PD, Meng G, Salazar-Gonzalez JF, Shaw GM. Macrophage HIV-1 infection and the gastrointestinal tract reservoir. J Leukoc Biol. 2003;74:642-9.

29. Toccalino H, O'Donnel JO. Tecnica para la introducion dela sonda cápsula de Crosby em niños. Rev Hosp Niños (Buenos Aires). 1962;12:29-30.

30. Ullrich R, Zeith M, Heise W, L'Age M, Hoffken G, Riecken EO. Small intestinal structure and function in patients infected with human immunodeficiency virus (HIV): evidence for HIV-induced enteropathy. Ann Intern Med. 1989;111:15-21

Recebido em 5/4/2005. Aprovado em 17/7/2006. 